\title{
Design, data, and theory regarding a digital hand inclinometer: a portable device for studying slant perception
}

\author{
Zhi Li • Frank H. Durgin
}

Published online: 7 February 2011

(C) Psychonomic Society, Inc. 2011

\begin{abstract}
Palm boards are often used as a nonverbal measure in human slant perception studies. It was recently found that palm boards are biased and relatively insensitive measures, and that an unrestricted hand gesture provides a more sensitive response (Durgin, Hajnal, Li, Tonge, \& Stigliani, Acta Psychologica, 134, 182-197, 2010a). In this article, we describe an original design for a portable lightweight digital device for measuring hand orientation. This device is microcontroller-based and uses a micro inclinometer chip as its inclination sensor. The parts are fairly inexpensive. This device, used to measure hand orientation, provides a sensitive nonverbal method for studying slant perception, which can be used in both indoor and outdoor environments. We present data comparing the use of a free hand to palm-board and verbal measures for surfaces within reach and explain how to interpret free-hand measures for outdoor hills.
\end{abstract}

Keywords Slant perception - Geographical slant .

Proprioception · Manual gesture $\cdot$ Digital inclinometer

Measuring the perception of surface orientation often depends on overt verbal or nonverbal judgments (e.g., Li \& Durgin, 2009). Nonverbal measures can be an important tool for avoiding numeric response attractors (like the tendency for verbal estimates to be multiples of five or ten). Gibson (1950) developed a palm board as a nonverbal approach to measuring perceived slant. His palm board was intended as a means of assessing a hand gesture (Gibson, 1986) and was used to study the perceived orientation of

Z. Li $\cdot$ F. H. Durgin $(\square)$

Department of Psychology, Swarthmore College,

500 College Ave.,

Swarthmore, PA 19081, USA

e-mail: fdurgin1@swarthmore.edu planar surfaces that were near vertical. Among nonverbal measures, an advantage of gestures over visual matching is, for example, that gestures can be made without looking away from the surface to be judged.

Palm boards are still widely used in slant perception studies (e.g., Norman, Crabtree, Bartholomew, \& Ferrell, 2009), especially those measuring perceived outdoor geographical slants (hillsides), in which the palm boards are typically set at the waist level of the participants (Bhalla \& Proffitt, 1999; Creem-Regehr, Gooch, Sahm, \& Thompson, 2004; Feresin \& Agostini, 2007; Proffitt, Bhalla, Gossweiler, \& Midgett, 1995). However, some controversy has arisen recently over the interpretation of the palm-board measure. Under full-cue conditions, Durgin, Hajnal, Li, Tonge, and Stigliani (2010a) found that participants set palm boards much too low when trying to match slanted surfaces that were within reach of the hand. The matching gain of the palm boards was only about 0.60 . In contrast, when participants were asked to orient their unseen hand freely in the air to match the same slants, the matching gain became nearly perfect (about 0.98 ). The much lower gain of the palm boards was not due solely to its height being set too low, because changing the relative height of the palm board only shifted the offset of the matching data without substantially changing the gain (Durgin, Hajnal, et al., 2010a; He, Hong, \& Ooi, 2007). Durgin, Hajnal, et al. (2010a) suggested that the low gain of palm boards was due to miscalibration of wrist-joint flexion. They found that the proprioception of wrist flexion is exaggerated, with a gain of nearly 2 . Because the axis of a palm board is fixed, users have to depend primarily on wrist rotation to control the palm-board orientation (unless they reposition their shoulder). Thus, the exaggerated perception of wrist flexion causes observers to set palm boards very low. In contrast, when signaling orientation with an unrestricted hand gesture, the elbow 
and wrist may be used together. Such gestures are well calibrated for surfaces in reach (Durgin, Hajnal, et al., 2010a; Durgin, Li, \& Hajnal, 2010).

A free-hand gesture not only has a higher gain than the palm-board measure but is also more sensitive than palm boards (i.e., has a lower variance relative to its gain; Durgin, Hajnal, et al., 2010a). These advantages suggested that the free-hand measures might serve to replace palm boards as a nonverbal method of choice for slant research. Some have tried to develop improved palm boards (Feresin, Agostini, \& Negrin-Saviolo, 1998), but the best option may be to eliminate them. Indeed, when Gibson first developed the palm board, he intended it as a way to measure hand/palm orientations. As he wrote later, "the slant . . . could be judged by putting the palm of the hand at the same inclination from the frontal plane and recording it with an adjustable 'palm board" " (Gibson, 1986, p. 165). In other words, a free-hand gesture is what a palm board was meant to measure. To get rid of the distorting restrictions of the palm board, it is necessary to find an easy way to measure hand orientation.

Two methods were employed in previous studies to measure hand orientation in free-hand gestures. Bridgeman and Hoover (2008), Durgin, Hajnal, et al. (2010a), and Hajnal, Abdul-Malak, and Durgin (in press) all used digital photographs to capture the orientation of hand or forearm gestures. Photography is a practical method, but it needs careful preparation to set up the camera and reference vectors (e.g., a vertical or horizontal bar) and requires offline image processing that may introduce additional bias and noise. An optical tracking system, such as the Vicon system used by Durgin, Hajnal, et al. (2010a; see also Durgin, Li, \& Hajnal, 2010) is convenient to use and has relatively high precision, but it is expensive and only appropriate for an indoor environment. In this article, we introduce a novel, light-weight digital device that precisely measures hand orientation. This digital hand inclinometer is portable, easy to use, and inexpensive. We propose that using this device to monitor free-hand gestures provides a method for studying human slant perception indoors or outdoors.

\section{Device design}

The inclination sensor of the digital hand inclinometer is a 3D MEMS ("3D integration of micro electromechanical systems") based, single-axis inclinometer-VTI SCA61T (Fig. 1). This inclinometer chip is fairly small and light $(10.5 \times 11.3 \times 5.1 \mathrm{~mm}$, and only $1-2 \mathrm{~g})$, which can be attached to the back of the hand easily without interfering with hand movements. The nominal measuring range of SCA61T is $\pm 90^{\circ}$, but the working range is $\pm 70^{\circ}$, which can adapted to the requirements of a gesture experiment (e.g., to $-20^{\circ}$ to $120^{\circ}$ of hand inclination, when mounted at a $50^{\circ}$

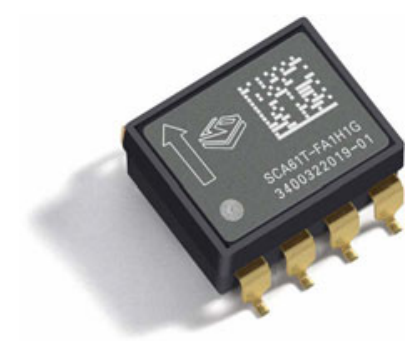

Fig. 1 VTI SCA61T inclinometer chip

orientation to the hand). The power requirement for this chip is extremely low (less than $20 \mathrm{~mW}$ ), which gives it a significant advantage in a battery-operated device. The retail unit price of SCA61T is only 49 US dollars.

A built-in inertial sensor inside SCA61T measures the inclination angle along one of its axes, and the integrated circuits inside the chip code the measured inclination angle to an analog voltage signal. We built an electronic circuit to convert the voltage signals back to inclination angles and display the values onto four 7-segment LED displays. To convert the voltage signals back to inclination values, we used an 8-bit microcontroller (PIC18F4523, Microchip Co.), which is integrated with a built-in 12-bit analog-todigital (A/D) converter. The conceptual diagram of the circuits is shown in Fig. 2. The actual circuit diagram is shown in Fig. 3.

The SCA61T chip was designed to obtain the maximum precision around level inclination. The output voltage signals and the actual inclinations follow a sinusoidal relationship. The analog output voltage $\left(\mathrm{V}_{\text {out }}\right)$ can be transformed to orientation $(\theta)$ by the following equation:

$\theta=\sin ^{-1}\left(\frac{V_{\text {out }}-\text { Offset }}{\text { Sensitivity }}\right)$,

where Offset is the output voltage at the $0^{\circ}$ inclination position and Sensitivity is $2 \mathrm{~V} / \mathrm{g}$ (nominal value) for the SCA61T chip we used.

Because of the sinusoidal coding of SCA61T and the discrete $\mathrm{A} / \mathrm{D}$ sampling, the measuring precision of the chip varies with the inclination range. Theoretically, with a 12-bit $\mathrm{A} / \mathrm{D}$ converter, the measuring precision at level inclinations up to $\pm 70^{\circ}$ should be below $0.1^{\circ}$, the precision between $\pm 70^{\circ}$ and $\pm 80^{\circ}$ should be below $0.2^{\circ}$, the precision between $\pm 80^{\circ}$ and $\pm 85^{\circ}$ should be below $0.4^{\circ}$, and the precision above $\pm 85^{\circ}$ should be between $0.5^{\circ}$ and $1.8^{\circ}$ (see Fig. 4). That is, theoretically, the SCA61T chip should be able to measure inclination between $-85^{\circ}$ and $85^{\circ}$ with an acceptable precision for most applications (i.e., less than $0.5^{\circ}$ ).

For high inclinations - for instance, higher than $80^{\circ}-$ the observed measuring precision is much greater than $0.2^{\circ}$, 
Fig. 2 Conceptual diagram of the digital hand inclinometer

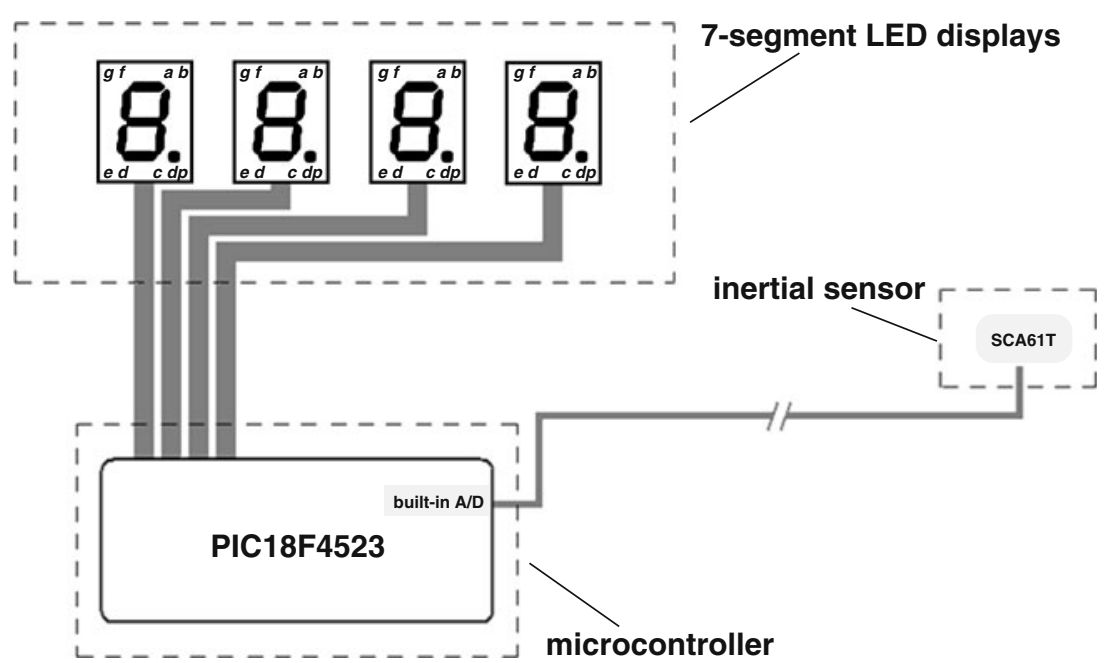

which means that high-frequency noise in the output of SCA61T makes the reading of the inclinometer unstable. To reduce the influence of high-frequency noise, two strategies are adopted. First, an RC low-pass filter circuit is added at the output of the SCA61T to smooth its voltage output, and a big capacitor is added between VDD and GND to reduce high-frequency noise in the supply voltage (see Fig. 3). Second, every 1,200 samples of the SCA61T
Fig. 3 Actual circuit of the digital hand inclinometer
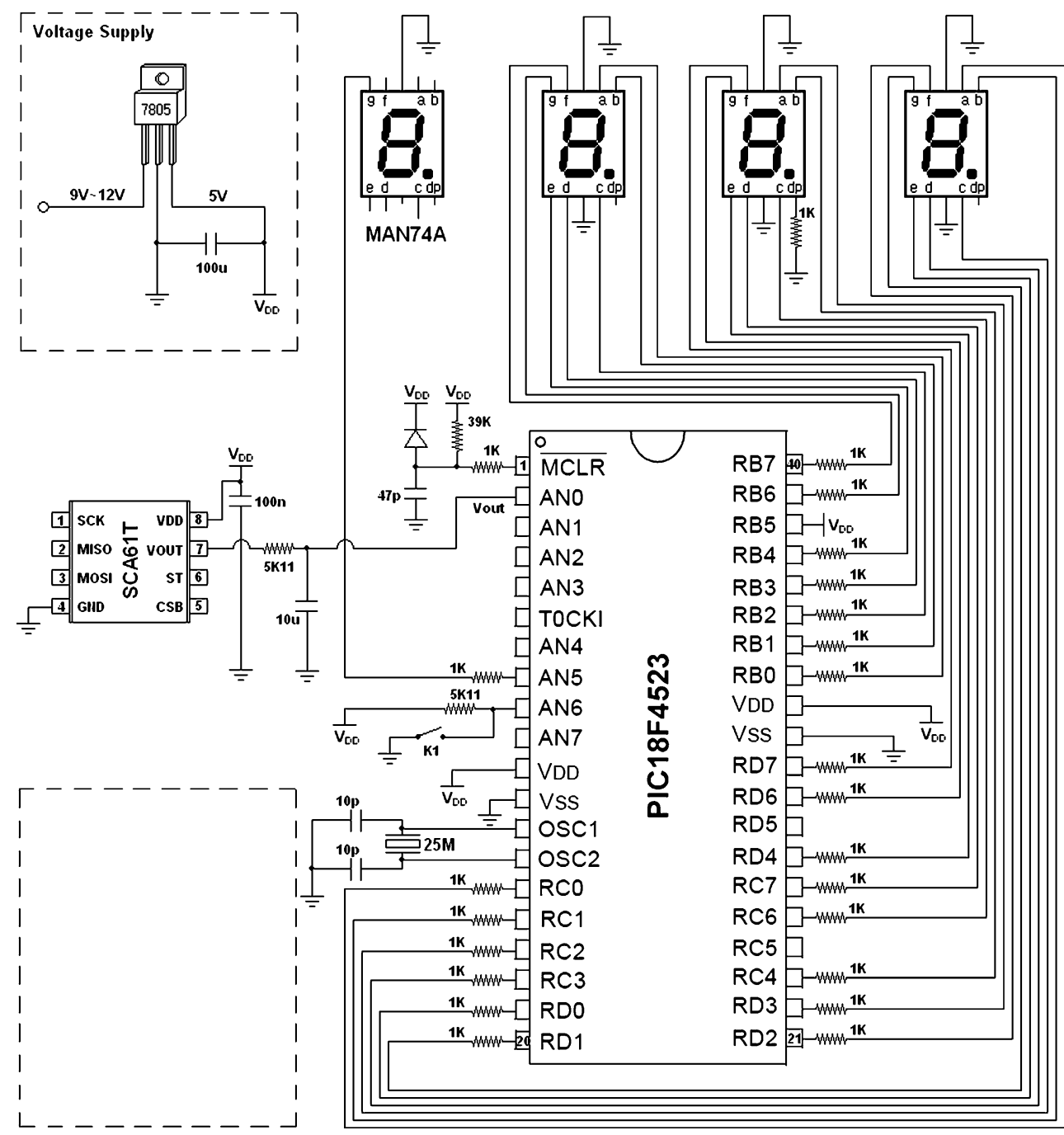
Fig. 4 Theoretical precision for the sinusoidal inclination coding with a 12-bit A/D converter

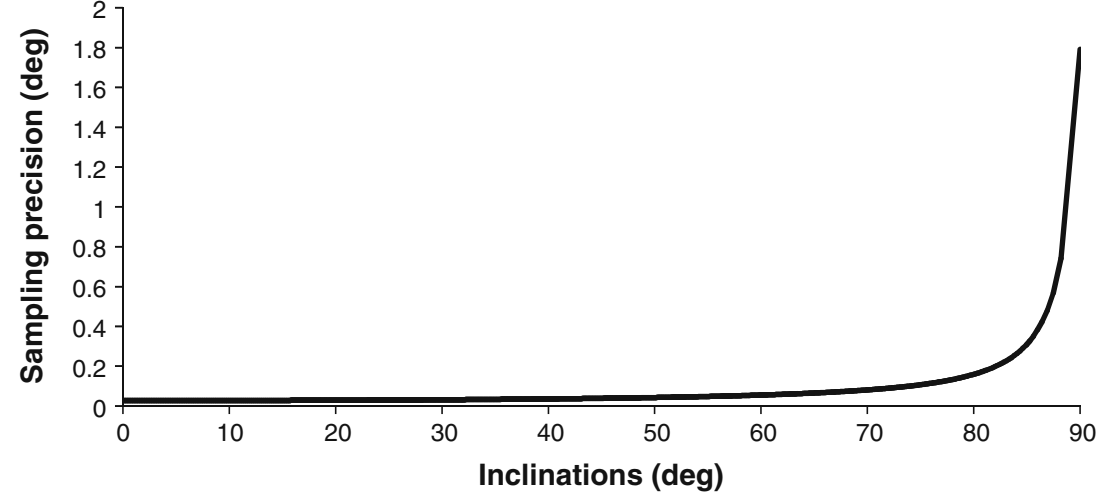

output voltage are averaged before the averaged voltage is converted to the inclination angle that is to be displayed. Thus, the influence of high-frequency noise in the circuits is further reduced, but the refresh rate of the LED display is dropped to about 2-3 Hz. The flowchart of the microcontroller program is shown in Fig. 5.

\section{Calibration}

As is shown in Eq. 1, the measured inclination, $\theta$, depends on the output voltage of the SCA61T and two constantsthe offset and the sensitivity. The nominal offset value is $2.5 \mathrm{~V}$, and the nominal sensitivity value is $2 \mathrm{~V} / \mathrm{g}$. Ideally, the supply voltage of SCA61T is $5.0 \mathrm{~V}$, and the voltage output ranges from $0.5 \mathrm{~V}$ (at $-90^{\circ}$ inclination) to $4.5 \mathrm{~V}$ (at $90^{\circ}$ inclination). Thus, the offset is the middle point of the output voltage range - that is, nominal offset $=(4.5 \mathrm{~V}+0.5 \mathrm{~V}) / 2$ -

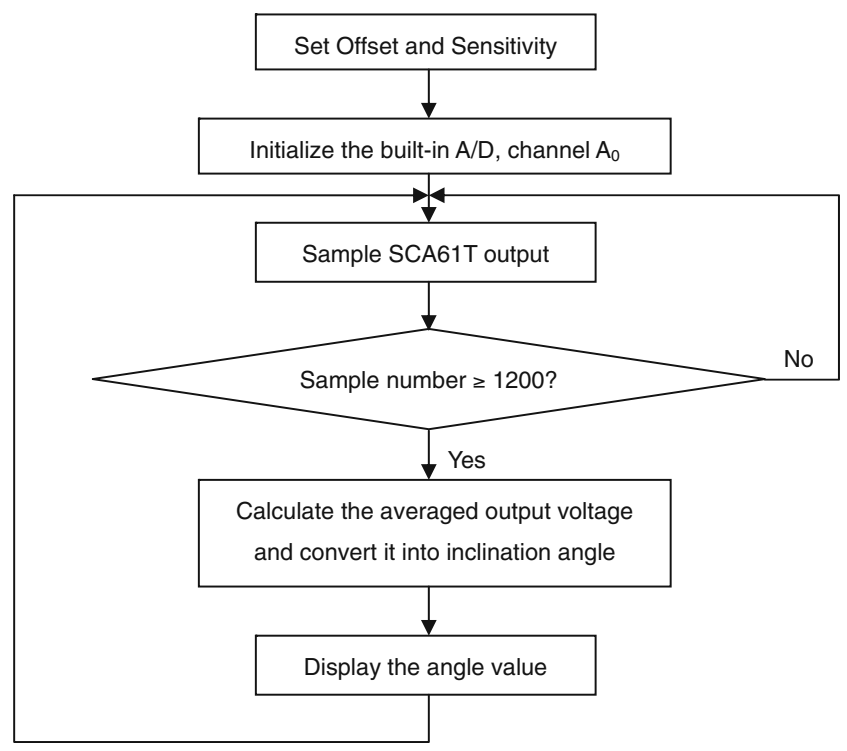

Fig. 5 Flowchart of the microcontroller program used in the digital hand inclinometer and sensitivity is half the output voltage range-that is, nominal sensitivity $=(4.5 \mathrm{~V}-0.5 \mathrm{~V}) / 2$. Because the actual voltage output range is usually different from the nominal value and also different for individual SCA61T chips, the output voltage range has to be measured directly for a given SCA61T chip, and the values programmed into the microcontroller. The offset and sensitivity values can be calculated according to Equation 2.

Offset $=\frac{\left(V_{90^{\circ}}+V_{-90^{\circ}}\right)}{2}$, Sensitivity $=\frac{\left(V_{90^{\circ}}-V_{-90^{\circ}}\right)}{2}$,

where $V_{90^{\circ}}$ is the voltage output for $90^{\circ}$ and $V_{-90^{\circ}}$ is the voltage output for $-90^{\circ}$.

\section{Prototype}

A photograph of a prototype hand inclinometer is shown in Fig. 6. The total cost of all parts was less than 100 US dollars. The SCA61T chip was soldered on a PCB board wrapped with electrostatic tape. The sensor is about $4.5 \times$ $4.5 \times 0.6 \mathrm{~cm}$ in size and only weights a few grams. The prototype can be powered by any DC voltage power supply with voltage input from 6 to $20 \mathrm{~V}$ or by a battery with the same voltage range. We tested this prototype with a $7.2-\mathrm{V}$ $\mathrm{Ni}-\mathrm{MH}$ rechargeable battery $(1,100 \mathrm{mAh})$, with which the hand inclinometer can work continuously for $5 \mathrm{~h}$ without loss of calibration. The sensor can be attached to the back of the hand with medical tape. A lightweight Velcro bracelet was used to secure the output wire at the wrist.

Performance of the prototype hand inclinometer was tested by attaching its sensor, along with a standard inclinometer (Craftsman Digital Torpedo Level), to the surface of a palm board. Orientation of the surface was set from $-85^{\circ}$ to $85^{\circ}$ with about $10^{\circ}$ increments. Readings from both inclinometers are shown in Table 1 . The reading difference between the two inclinometers is less than $0.3^{\circ}$ in the inclination range from $-70^{\circ}$ to $70^{\circ}$, and the difference is always less than $0.5^{\circ}$ when the inclination angle range is between $-85^{\circ}$ and $85^{\circ}$. 


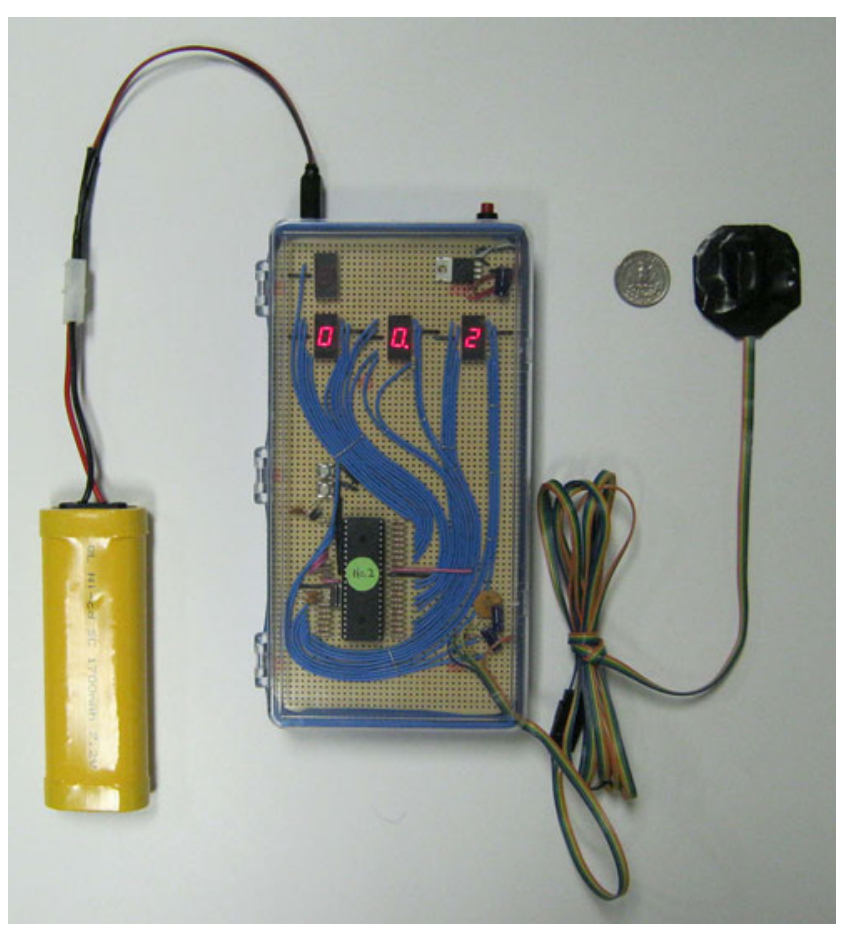

Fig. 6 Photograph of a prototype digital hand inclinometer

\section{Comparison of free-hand with palm-board and verbal measures}

We have recently reported studies comparing the free-hand measure with a waist-high palm board (Durgin, Hajnal, et al., 2010a) and with verbal reports for real surfaces viewed under full-cue conditions within reach of the hand (Durgin, Li, and Hajnal, 2010). In both studies, it was found that the gain of the estimates using a free hand was very nearly 1 , whereas the gain for the palm board was less than 1 (Durgin, Hajnal, et al., 2010a), and the gain for verbal estimates was greater than 1 for angles between $0^{\circ}$ and $60^{\circ}$ (Durgin, Li, \& Hajnal, 2010). Durgin, Li, \& Hajnal argued that although verbal estimates and nonverbal angle bisection reports provided clear evidence that near surfaces appeared steeper than they were, free-hand measures showed good calibration to actual surface orientation because they are calibrated by visuomotor experience. Thus, we do not propose the free-hand measure as a read-out of visual experience, but as a kind of index of deviations from expected perceived orientation. For full-cue surfaces in near space, free-hand estimates tend to vary with actual slant with a gain very close to 1 .

To supplement these other studies, we here report a further study in which we collected free-hand measures, palm-board measures at chest level (to allow more flexibility of movement than is available at waist level), and verbal reports of the orientation of real surfaces $\left(12^{\circ}\right.$ $66^{\circ}$ from horizontal) under full-cue conditions. We conducted the study at two distances, one within reach of the surface (and with the palm-board axis aligned so that the palm board could be set in the actual plane of the real surface), and one from a meter farther back. An occluding barrier meant that neither the hand nor the palm board was visible to the participant. Both the palmboard and free-hand measures were corrected to the orientation of the palm of the hand (see Appendix A). Although the palm board tended to be closer to accurate when it was mounted near the plane of the surface (gain = 0.94 ) than when it was not (gain $=0.81$ ), this difference was not reliable, $t(18)=1.43, p=.1698$, so the data are collapsed here across the two distances. In Table 2, we report the mean intercepts and gains for linear fits to the data of each of 20 participants. We also show mean parameters for power-function fits to individual participants (Durgin \& Li, 2010). For the free-hand measure, neither the mean gain (slopes of linear models) nor the mean power function exponent (slopes in log-log space) differed reliably from $1, t(19)=1.27, p=.2205 ; t(19)=$ $0.15, p=.8815$. This shows, once again, that the free hand is quite well calibrated to the orientations of near surfaces. In contrast, the mean palm-board gain was reliably less than $1, t(19)=2.72, p=.0135$, and the mean palm-board exponent was reliably greater than $1, t(19)=4.71, p=.0002$. As found in an earlier study (Durgin, Li, \& Hajnal, 2010), the mean gain for the verbal measure is reliably greater than $1, t(19)=9.58, p<.0001$, as is the mean exponent for the verbal measure, $t(19)=3.49, p=.0024$.

Durgin, Hajnal, et al. (2010a) found that palm-board estimates varied as a function of the height of the palm board. Here we used a higher palm-board position than had been used by Durgin, et al. (2010a), but we observed a trend for palm-board estimates to differ as a function of whether the palm board could be set in the same part of

Table 1 Comparison between the prototype hand inclinometer and a standard inclinometer

\begin{tabular}{|c|c|c|c|c|c|c|c|c|c|c|}
\hline Craftsman & $0.0^{\circ}$ & $10.0^{\circ}$ & $20.1^{\circ}$ & $29.9^{\circ}$ & $40.1^{\circ}$ & $50.0^{\circ}$ & $60.0^{\circ}$ & $69.9^{\circ \circ}$ & $79.9^{\circ}$ & $84.8^{\circ}$ \\
\hline SCA61T & $0.0^{\circ}$ & $9.9^{\circ}$ & $20.0^{\circ}$ & $29.8^{\circ}$ & $39.9^{\circ}$ & $49.9^{\circ}$ & $59.9^{\circ}$ & $70.0^{\circ}$ & $80.1^{\circ}$ & $84.9^{\circ}$ \\
\hline Craftsman & $0.0^{\circ}$ & $-10.0^{\circ}$ & $-20.0^{\circ}$ & $-30.1^{\circ}$ & $-40.1^{\circ}$ & $-50.0^{\circ}$ & $-60.0^{\circ}$ & $-70.0^{\circ}$ & $-79.9^{\circ}$ & $-84.9^{\circ}$ \\
\hline SCA61T & $0.0^{\circ}$ & $-10.0^{\circ}$ & $-19.9^{\circ}$ & $-29.8^{\circ}$ & $-39.9^{\circ}$ & $-49.7^{\circ}$ & $-59.7^{\circ}$ & $-69.7^{\circ}$ & $-79.4^{\circ}$ & $-84.6^{\circ}$ \\
\hline
\end{tabular}


Table 2 Comparison of free-hand with palm-board and verbal responses

\begin{tabular}{llllll}
\hline & \multicolumn{2}{l}{ Linear Model } & & \multicolumn{2}{l}{ Power Function Model } \\
\cline { 2 - 3 } \cline { 6 - 7 } & Intercept $^{\mathrm{a}}$ & Gain $^{\mathrm{b}}$ & & Constant $^{\mathrm{a}}$ & Exponent $^{\mathrm{b}}$ \\
\hline Free Hand & 0.09 & 1.06 & & -0.02 & 1.02 \\
Verbal & -2.89 & $1.34^{* *}$ & & $-0.06^{*}$ & $1.34^{* *}$ \\
Palm Board & $-7.46^{* *}$ & $0.87^{*}$ & & $-0.62^{* *}$ & $1.22^{* *}$ \\
\hline
\end{tabular}

${ }^{\mathrm{a}}$ Means across 20 participants; statistical comparison is to $0 .{ }^{\mathrm{b}}$ Means across 20 participants; statistical comparison is to $1 .{ }^{*} p<.05$. ${ }^{* *} p<.01$.

space as the target surface. This may be because absolute position information could be matched (see Hajnal et al., in press). In contrast, the free-hand measure was clearly not affected by the different viewing positions. Although a freehand measure may not be perfect, we have observed that it can be a very useful benchmark (accurate under full-cue conditions), even without any training of participants (Durgin, Hajnal, et al., 2010a; Durgin, Li, \& Hajnal, 2010).

\section{Use of the free-hand measure with outdoor hills}

When studying outdoor hills, the free-hand measure will no longer accurately reflect the true slant of the hill, but should continue to provide a basis for comparing hill perception to the perception of near surfaces. It should not accurately reflect actual hill orientation, because hills appear much steeper than near surfaces of the same orientation (Bridgeman \& Hoover, 2008; Li \& Durgin, 2010), and the free-hand measure is well calibrated for near surfaces. Bridgeman and Hoover used a related measure for their study of outdoor hills (they used digital photography to measure the orientation of a raised forearm) and reported that their forearm measure gave estimates of slant, though lower than verbal estimates, that were much higher than the actual slant of the hill. This is consistent with our findings using the free-hand measure (e.g., Durgin, Hajnal, et al., 2010a, Exp. 2; Stigliani, Durgin \& Li, 2010). However, because the free hand is calibrated for near surfaces, estimates made with respect to far surfaces can be understood as representing a near surface equivalent (NSE) measure of perceived hill orientation - the physical orientation of a near surface that would be judged equivalently.

We emphasize that we are not saying that the free-hand measure directly shows the perceptual experience of observers (see Durgin, Li, \& Hajnal, 2010, for a discussion), nor is it an "action measure" that shows the motor representation of the surface (see Durgin, Hajnal, Li, Tonge, \& Stigliani, 2010a, 2010b). Rather, we propose that the free hand provides a bridge to the perceived orientation of far surfaces, like hills, by indicating the near surface orientation that would be judged equivalent in slant.

To illustrate this idea, we used data from a recent study by Stigliani et al. (2010). They collected verbal estimates and free-hand measures of outdoor hills using the present device for a set of campus paths ranging from nearly flat $\left(0.5^{\circ}\right)$ to fairly steep $\left(8.6^{\circ}\right)$. Note that the perceived orientation of any specific outdoor hill may depend on a variety of factors in addition to its physical slant (e.g., curvature and viewing distance), but if the free-hand measure represents the NSE orientation, we should expect the relationship between verbal estimates and free-hand (NSE) estimates to remain similar to that observed for near surfaces. In other words, we should be able to make a prediction about the verbal estimates based on the free-hand estimates.

Figure 7 shows Stigliani et al.'s (2010) numeric estimation data for outdoor slopes plotted against the corresponding free-hand estimates (NSE) for each physical path (the physical path inclination is shown next to each data point). The linear fit to the numeric data relative to the free-hand measure of NSE (intercept of $-2.4^{\circ}$, gain of 1.35) corresponds nearly exactly to that shown in Table 2 for verbal estimates of near surface orientation (intercept of -2.9 , gain of 1.34). Thus, the relationship of numeric estimates to freehand measures is maintained for far surfaces like hills, even while they are perceived as steeper than near surfaces. Consider an example: Stigliani et al.'s data suggest that the $8.6^{\circ}$ path they studied appeared equivalent in orientation to a surface of $22^{\circ}$ within reach, and was therefore judged to be

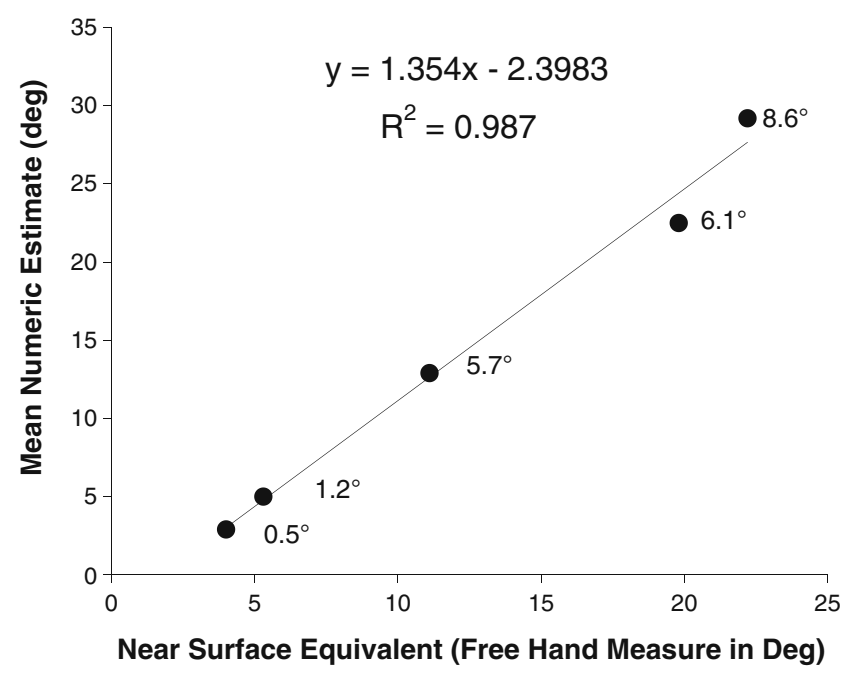

Fig. 7 Verbal estimation data plotted as a function of free-hand data (near surface equivalents) for outdoor hills (Stigliani et al., 2010). The actual path inclination is shown next to each data point. For hills, a free-hand measure provides an indication of the equivalent near surface orientation that would be perceived as equivalent in orientation. Verbal estimates form the same function with respect to these near surface equivalents as to the near surfaces 
$29^{\circ}$ by verbal estimation (as would a surface of $22^{\circ}$ presented within reach).

We reiterate that, when used for hills, the free-hand measure is neither an action measure nor a direct measure of perceived slant. The virtue of the free-hand measure is that it provides a sensitive nonverbal method for assessing slant perception of far surfaces, such as hills. It allows one to relate those perceptions to the perception of near surfaces, to which free-hand estimates are well calibrated (see also Durgin, Hajnal, et al., 2010a, 2010b).

\section{Conclusion}

In this article, we described the design of a portable digital hand inclinometer that can be used to measure hand orientation. We also provide further evidence to confirm that this device can be used to replicate prior findings that, for near surfaces, unrestricted hand gesturing reflects changes in real surface orientation with a gain of essentially 1. Combining the hand inclinometer with unrestricted hand gesturing provides a sensitive nonverbal method for studying human slant perception, which is especially suitable for outdoor environments. We propose that freehand gestures be interpreted as reflecting the "near surface equivalent" orientations of far surfaces.

Author Note This research was supported by Award R15EY021026 from the National Eye Institute. The content is solely the responsibility of the authors and does not necessarily represent the official views of the National Eye Institute or the National Institutes of Health. This work was also supported by Hans Wallach fellowship funds and by a Swarthmore College Faculty Research Grant. We are grateful to the Psychology Department of Swarthmore College for their support.

\section{Appendix A. Methods and orientation data of the experiment: Comparison of free-hand with palm-board and verbal measures}

Method

\section{Participants}

Twenty Swarthmore College students (9 females) participated in this experiment, fulfilling a course requirement. All had normal or corrected-to-normal vision.

\section{Design}

Stimulus surfaces were presented at participants' chest level with a viewing distance (to the center of the surfaces) of about either 0.5 or $1.5 \mathrm{~m}$. Ten participants (5 females) participated in the $0.5-\mathrm{m}$ distance condition, and the other 10 (4 females) participated in the $1.5-\mathrm{m}$ condition. Each participant participated in three blocks for a total of 20 trials. Eleven participants ( 6 in the $0.5-\mathrm{m}$ condition) used the free-hand measure in the first block and the palm-board measure in the second block. The other 9 ( 4 in the $0.5-\mathrm{m}$ condition) used the palm-board measure in the first block and the free-hand measure in the second. All participants made verbal estimates of the slant in the third block. Five slants $\left(12^{\circ}, 24^{\circ}, 36^{\circ}, 48^{\circ}\right.$, and $\left.60^{\circ}\right)$ were tested in the first block; a different set of five slants $\left(18^{\circ}, 30^{\circ}, 42^{\circ}, 54^{\circ}\right.$, and $66^{\circ}$ ) were tested in the second block. All ten slants were then tested once more in the third block. Within each block, the slants were shown in a random order.

\section{Apparatus}

The stimulus surfaces were irregular-shaped wooden boards manually placed on a metal slope-presentation device that allowed the experimenter to quickly and accurately set the wooden board to a predetermined angle (see Durgin et al., 2010; Li \& Durgin, 2009).

Free-hand measure The digital hand inclinometer was attached to the back of a participant's hand to measure the hand orientation. A horizontal surface was set at the participant's navel level, which was used for calibration of the hand inclinometer and also to indicate the level orientation to the participants. A black barrier was used to block the hand and arm of the participants.

Palm-board measure A low-friction palm board (see Durgin et al., 2010a) was set at the participants' chest level about $0.5 \mathrm{~m}$ in front of them. In the $0.5-\mathrm{m}$ distance condition, the palm-board axis was aligned to the stimulus surface so that the palm board could be set in the actual plane of the stimulus surface. In the $1.5-\mathrm{m}$ distance condition, the palm board was set at the same height, but $1 \mathrm{~m}$ back from the stimulus surface (i.e., the relative position between the palm board and the participants remained the same in both viewing distance conditions). A clamp was used on the palm board to make a stop at level orientation. A black barrier was used to block the palm board from the participant's view. A protractor on the side wall of the palm board indicated the orientation of the palm-board surface. The digital hand inclinometer was also attached to the back of the participant's hand to provide a second measure of the hand orientation.

\section{Procedure}

Before each trial, participants were asked to close their eyes while the experimenter changed the stimulus board and its 
slant. Then, the participants were allowed to open their eyes and indicate the slant of the stimulus surface by using a free-hand, palm-board, or verbal measure. For the free-hand measure, participants flattened their right hand on the level surface at the beginning of each trial, and the initial orientation of the back of their hand was recorded. Then, they lifted their right hand up from the surface and rotated it (using mainly their elbow) until they felt their hand orientation matched the surface orientation. This final orientation of the back of their hand was then recorded. The difference between the final and initial orientations of the back of the hand determined the orientation of the palm when participants matched their hand to the surface. In the palm-board measure, participants flattened their right hand on the palm-board surface, which always started at level orientation (by means of a fixed stop) at the beginning of each trial, and the orientation of the back of their hand was recorded. Participants rotated the palm board until they felt that it was parallel with the stimulus surface. The palm- board orientation (read from the protractor) and the orientation of the back of their hand (read from the digital hand inclinometer) were then recorded. For the verbal measure, participants gave verbal estimates (in degrees) of the slant of the surface they saw.

\section{Results}

Averaged slant estimation data of the three methods are plotted as a function of actual slant in Fig. A1. For the palm-board measure, the hand inclinometer data are shown in Fig. A1, because readings from the protractor and the digital hand inclinometer used with the palm board were essentially identical. Linear regression functions of the data are also shown in Fig. A1, with different colors representing different measuring methods. The differences between the three measures are discussed in the main text.
Fig. A1 Comparison of the free-hand, palm-board, and verbal measures at two viewing distance conditions (left panel, $0.5-\mathrm{m}$ distance condition; right panel, $1.5-\mathrm{m}$ distance condition) Error bars are standard errors
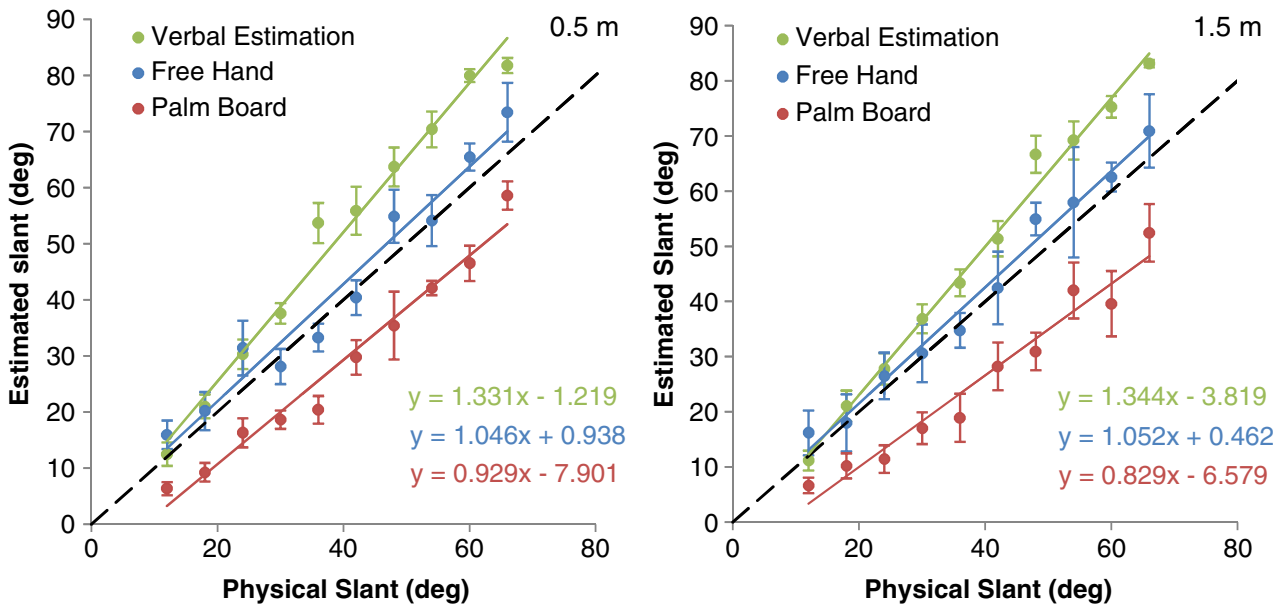

\section{References}

Bhalla, M., \& Proffitt, D. R. (1999). Visual-motor recalibration in geographical slant perception. Journal of Experimental Psychology: Human Perception and Performance, 25, 10761096.

Bridgeman, B., \& Hoover, M. (2008). Processing spatial layout by perception and sensorimotor interaction. The Quarterly Journal of Experimental Psychology, 61, 851-859.

Creem-Regehr, S. H., Gooch, A. A., Sahm, C. S., \& Thompson, W. B. (2004). Perceiving virtual geographical slant: Action influences perception. Journal of Experimental Psychology: Human Perception and Performance, 30, 811-821.

Durgin, F. H., Hajnal, A., Li, Z., Tonge, N., \& Stigliani, A. (2010a). Palm boards are not action measures: An alternative to the two-systems theory of geographical slant perception. Acta Psychologica, 134, 182-197. doi:10.1016/j.actpsy.2010.01.009
Durgin, F. H., Hajnal, A., Li, Z., Tonge, N., \& Stigliani, A. (2010b). Not all dissociations are theoretically important: More evidence for the generalizability of the observations of Durgin et al. (2010). Acta Psychologica. doi:10.1016/j.actpsy.2010.09.002

Durgin, F. H., \& Li, Z. (2010). Controlled interaction: Strategies for using virtual reality to study perception. Behavior Research Methods, 42, 414-420.

Durgin, F. H., Li, Z., \& Hajnal, A. (2010). Slant perception in near space is categorically biased: Evidence for a vertical tendency. Attention, Perception, \& Psychophysics, 72, 1875-1889.

Feresin, C., \& Agostini, T. (2007). Perception of visual inclination in a real and simulated urban environment. Perception, 36, 258-267.

Feresin, C., Agostini, T., \& Negrin-Saviolo, N. (1998). Testing the validity of the paddle method for the kinesthetic and visualkinesthetic perception of inclination. Behavior Research Methods, Instruments, \& Computers, 30, 637-642.

Gibson, J. J. (1950). The perception of visual surfaces. The American Journal of Psychology, 63, 367-384. 
Gibson, J. J. (1986). The ecological approach to visual perception. Hillsdale: Erlbaum.

Hajnal, A., Abdul-Malak, D. T., \& Durgin, F. H. (in press). The perceptual experience of slope by foot and by finger. Journal of Experimental Psychology: Human Perception and Performance. doi:10.1037/a0019950

He, Z. J., Hong, J., \& Ooi, T. L. (2007). On judging surface slant using haptic (palmboard) and verbal-report task [Abstract]. Journal of Vision, 7(9), 282a. doi:10.1167/7.9.282

Li, Z., \& Durgin, F. H. (2009). Downhill slopes look shallower from the edge. Journal of Vision, 9(11), 6:1-15. doi:10.1167/ 9.11 .6
Li, Z. \& Durgin, F. H. (2010). Perceived slant of binocularly-viewed large-scale surfaces: A common model from explicit and implicit measures. Journal of Vision, 10(14), 13:1-16. doi:10.1167/10.14.13

Norman, J. F., Crabtree, C. E., Bartholomew, A. N., \& Ferrell, E. L. (2009). Aging and the perception of slant from optical texture, motion parallax, and binocular disparity. Attention, Perception, \& Psychophysics, 71, 116-130.

Proffitt, D. R., Bhalla, M., Gossweiler, R., \& Midgett, J. (1995). Perceiving geographical slant. Psychonomic Bulletin \& Review, 2, 409-428.

Stigliani, A., Durgin, F., \& Li, Z. (2010). How accurate is memory for familiar slope? [Abstract]. Journal of Vision, 10(7), 1245a. doi:10.1167/10.7.1245 